\title{
Traveler Satisfaction in Rapid Rail Systems: The Case of Istanbul Metro
}

\author{
SedaYanık ${ }^{1}$, Emel Aktas ${ }^{2 *}$, Ilker Topcu ${ }^{1}$ \\ ${ }^{1}$ Industrial Engineering Department, Istanbul Technical University, Istanbul, Turkey \\ ${ }^{2}$ Cranfield University, CranfieldSchool of Management, Cranfield, MK43 0AL, UK
}

\begin{abstract}
Multi-faceted characteristics of urban travel have an impact on thepassengers' overallsatisfaction with the transport system. In this study, we investigate the interrelationships among traveler satisfaction, travel and traveler characteristics, and service performancein a multimodal network that comprises of a trunk line and its feeder lines. We analyze the factors influencing the choices of access to rail transit stations and the satisfaction of transit travelers with the rapid rail transit systems. We quantitatively study these relationships and demonstrate the complexity of evaluating transit service performance. Since the interrelationships among variables affecting this system are mainly stochastic, we analyzethe satisfaction with transit system problem using a Bayesian Belief Network (BBN), which helps capture the causality among variables with inherent uncertainty.Using the case of Istanbul, weemploy theBBN as a decision support tool for policy makers to analyzethe rapid rail transit services and determinepoliciesfor improving the quality and the level of serviceto increase the satisfaction with transit system.In the case study, satisfaction with accessibility and access mode variables are found to be more effective variables than total travel time for travel time satisfaction, confirming the significant role of access in multimodal travels.
\end{abstract}

Keywords: Trunk-and-Feeder Transportation Systems,Rapid Rail Systems, Traveler Satisfaction, Bayesian Belief Network

${ }^{*}$ Corresponding author. Tel.: +441234751122; e-mail address: emel.aktas@cranfield.ac.uk. 


\section{Introduction}

Public transport is a key aspect of sustainable transportation, allowing social mobility and enabling less pollution and congestion. To encourage a decreased use of private automobiles in urban areas, we need high quality public transport services (Olivkova, 2015).Transportation service quality is one of the key drivers of sustainable transportation policies and it depends on several qualitative and quantitative factors (Cascetta andCartenì, 2014). Transportation service providers measure traveler satisfaction to assess service level and quality. However, it is quite difficult to match subjective satisfaction of travelers with underlying reasons related to service and traveler characteristics. Recent efforts ontransportation planning and urban policymakinghaveoften focused on increasing transit ridership through improved technological, operational, and service efficiencies. Thegoal of increasing the share of transit would result in decreasedenvironmental stress with lower emissions and higher energy efficiencies as well as increased quality of life in urban areas owing toless congestion and less pollution; hence a sustainable transport system. To this end, urban rail systems offer major advantages for promoting the transit travel as a trunk line with high speeds, high capacities, and its own right-of-way. However, the characteristics of rail transit such as network coverage, tariffs, travel time, reliability, service schedule, and the station accessibility influence the ability and the willingness of travelers to make transit travels(Lindsey et al., 2010; Aydin et al., 2015).

The factors that influence the performance of transportation services are multi-faceted. Among them, many are stochastic in nature. Thus, these factors may be uncertain, the information about them may be incomplete, and their interrelationships may be non-linear. Moreover, these factorsareusuallycorrelated. For example, the performance of transportation service is a function of the usage of the service. The performance function is typically an increasing non-linear function of the flow, which is a random variable distributed across time 
and throughout the transportation network. Besides, perception of the performance of the transportation systems (e.g. travel time) is also a random variable distributed across the population of travelers. Therefore, there is a distinction between the actual performance and the perceived performance.

In this study, we focus on rapid rail transportation in the form of trunk and feeder systems. Connectivity between the trunk and feeder lines and the accessibility of the nodes in the multimodal network determine the overall spatial structure of the network, specifically, the coverage of the network. We present the factors and their influences on satisfaction with the rapid rail system in a network structure due to the complexity of interrelations between these factors. Among such networks, Bayesian Belief Networks (BBNs), influence diagrams, and qualitative probabilistic networks constitute some of the more prominent formalisms found in applied research (Aktas et al., 2007).To the best of our knowledge, BBN approach has only been used to deal with the cognition of locations in an urban setting (Arentze and Timmermans, 2005). In this study, we use this method to account for how individuals assess the transport system. We elicit the factors that affect the passengers' satisfaction with the public transport and establish the hierarchical relationships among these factors. Then, incorporating the BBN approach, we identify which factors contribute the most to the specific aspects of travel satisfaction to identify areas where public transport service could be improved. Specifically, we employ a BBN approach with a learning mechanism and use it as an alternative decision support tool for analyzing the rail rapid transit services and identifying policies to improve the travelers' level of service. Finally, we test the proposed methodology using the case of Istanbul Metro. We contribute to the extant literature on modeling travel behavior by proposing a new methodology for analyzing travel behavior where the traditional approaches on modeling travel behavior comprise of discrete choice analysis methods or 
structural equation models. We test the applicability of our proposed methodology with primary data using the case of Istanbul Metro.

We organize the paper as follows: Section 2 provides a brief literature review of public transportation systems and user satisfaction. Section 3 explains the methodology used in this research. Section 4 applies the proposed methodology to the case of Istanbul Metro. Section 5 discusses the results of the case study. Finally, Section 6 concludes the paper and provides suggestions for future studies.

\section{Literature Review}

The relevant literature pertaining to our work can be examined under mode choice and satisfaction. We start by addressing the mode choice behavior of travelers in Section 2.1 and then present relevant work on traveler satisfaction in Section 2.2.

\subsection{Travelers' mode choice}

Trunk-feeder systems reduce some of the inefficiencies generated by heavy flows of competing buses (United Nations Centre for Human Settlements, 1993). Feeder lines carry travelers from suburbs to the trunk where the travelers interchange for lines distributing to the city (Vassallo et al., 2012). The operation is reversed in the afternoon for travelers leaving work and going back home. In unimodal networks, accessibility is often restricted to distance or time of travel (Xie and Levinson, 2007). However, research has shown that, for example, Dutch railway travelers, in about $47 \%$ of the cases, did not choose the nearest departure station to their places of residence and considered accessibility together with the connecting lines (Debrezion et al., 2009). This result emphasizesthatvarious factors affect the travelers' choice of departure station and access mode in multimodal networks.

Transfers between lines are a major element of rapid rail systems and they are common in large urban multimodal networks. For instance, $70 \%$ of the travels including a metro trip in London have at least one transfer to another line (Transport for London, 2001). 
This rate, showing travels with at least one transfer, is 30\% in New York City, $70 \%$ in Munich, 40\% in Paris (Guo and Wilson 2011; GUIDE 1999; NYMTC 1998) and at least 60\% in Istanbul (Ugurlu, 2011).Metro systems are characterized by a high number of multimodal travelsand measures related to accessibility, complexity of the network, connectivity, and directness (Derrible and Kennedy, 2010).

Traveler characteristics and its relation to travel choice, ridership and satisfaction have been widely investigated in the literature. Shiftan et al. (2008) identify distinct market segments by modeling simultaneously travelers' attitudes, travel behavior, and the causal relationships between a traveler's socioeconomic profile and their attitude toward travel. Oña et al (2015) apply their methodology to different group of users of a suburban rail transit system to assess their perceptions about the services. The profiles of users are classified according to the type of users, the day of travel, the frequency of use, and the time of travel during the day. Roorda and Ruiz (2008) use longitudinal datasets and find an underlying similarity between a person's weekday activity/travel schedules from one year to the next and the latent variables, which are represented as a linear function of the socioeconomic characteristics of the person such as gender, income, and age. Vega and Feighan (2009) model the choice of residential location and travel-to-work mode by three different variable groups, namely property prices, travel-related attributes, and as socio-economic characteristics which are represented by number of cars, gender, and socio-economic group.

Travel characteristics are also used commonly to investigate the traveler choice, patronage, and satisfaction. Currie and Wallis (2008) synthesize the evidence to identify measures including travel related characteristics such as trip distance, trip purpose/time, and travel mode that are likely to grow patronage of bus services. Vega and Feighan (2009)integrate travel characteristics such as travel time and costs intomodeling the choice of residential location and travel-to-work mode. Similarly, Tyrinopoulos and Antoniou (2008) 
also use travel related attributes (e.g. travel time, waiting time, distance/time to access stop) to model the users' perceived satisfaction with public transit services. On the other hand, Oña et al (2015) analyze travel related attributes influencing service quality such as regularity and punctuality of the runs, safety, comfort, information on boards, and cleanliness of the cars and the seats. Chorus et al. (2007) investigate the quality of multimodal travel choices with respect to travel information along with multiple attribute-dimensions of alternatives, such as travel times and travel costs of car and transit alternatives, as well as waiting times and seat probabilities in transit.Carrel et al. (2016) use tracking data combined with daily surveys of passengers to examine the link between travel quality measures and passenger satisfaction using mode access variables, satisfaction surveys, travel times including wait times, and socio-demographic variables.

\subsection{Traveler satisfaction}

From a traveler perspective, a travel is often a chain of the trips undertaken to move from an origin (e.g. home) to a destination (e.g. work). Thereby, the travelerevaluatesnot only the availability of a transit service with its transfer connections, but also the performance of the transit service which depends on the level of service offered in connecting lines. Service quality is the level of match between the service delivery performance and the expectations of customers (Parasuraman et al., 1985). These expectations generally arise from the needs or characteristics of the individuals. In fact, travelers evaluate the transport services in various ways, using multiple criteria (Román et al., 2014). Using Parasuraman's SERVQUAL model, Celik et al. (2014) perform a multi-criteria decision analysis supported by fuzzy expert judgments for evaluating the level of satisfaction. Similarly, Aydin et al. (2015) develop a fuzzy analytical hierarchy process to measure rail transit line performance in Istanbul considering traveler satisfaction criteria such as train comfort, ticketing, information systems, accessibility, safety, station comfort, welcoming, fare, and time.Lai and Chen (2011) posit 
that it is not possible to guarantee passenger satisfaction if the quality of public transit service does not result in increased passenger perceptions of the value of travel. It is common to evaluate the performance of services with traveler satisfaction from various dimensions of the service (Brons et al. 2009; Chou and Kim 2009; Tyrinopoulosand Antoniou 2008; Currie and Wallis 2008; TCRP 1999). In the rail transit case, a traveler-oriented analysis of the performance of the rail transit service combines the characteristics and the connections of the rail transit service and analyzes how cooperatively they act with each other as well as how other exogenous factors affect this cooperative action.

Accessibility is an important aspect of rail journeys with influence on the overall satisfaction of the traveler (Brons et al., 2009). Olivkova (2015) states that the accessibility of stops is one of the factors with great impact on the overall passenger satisfaction.Previous research on accessibility of rail systems confirms that accessibility is a decision factor for the choice of travel mode (Rietveld, 2000; Givoni and Rietveld, 2007). Travelers' satisfaction with the rail journey is related to their satisfaction with the accessibility and this suggests that improving accessibility is likely to increase rail use. Brons et al. (2009) find that the quality of access facilities is even more important for infrequent rail travelers, and improved accessibility can increase infrequent travelers' use of rail system and attract new travelers.DeJonge and Teunter (2013) study the problem of finding an optimal itinerary to travel from a starting location to a destination location using public transport, where theyallowtravelers to alternate rides with short walks. This results in a reduced total travelling time; however, the authors call for further research since they do not consider the preferences of travelers. Similarly, Debrezion et al. (2006) useaccessibility, connectivity of stations, and population characteristics to develop a quality index for train services. Tyrinopoulos and Antoniou (2008) indicate the importance of providing further insight into the differences among groups of the population while assessing the quality implications of the variability of 
the users' perceived satisfaction with public transit services.Del Castillo and Benitez (2013) propose a satisfaction index including the dimensions of connectivity, accessibility, information, time satisfaction, user attendance, comfort, safety and security, and environmental impact. Structural Equation Modelling has been frequently used as a method to unveil the complex relationships between service quality, satisfaction, and loyalty in public transport. Shen et al. (2016) use structural equation modelling to account for the dependencies among the satisfaction variables.Van Lierop and El-Geneidy (2016) investigate the impact of public transit users' service quality perceptions and satisfaction on the loyalty, i.e. continued use of public transportation services. Yilmaz and Ari (2017) use structural equation modeling to analyze the loyalty of rail passengers incorporating functional and technical quality dimensions. De Ona et al. (2016) build a conceptual framework where behavioral intentions of passengers are explained by satisfaction with the service which is affected by service quality and the attractiveness of alternatives. They then empirically test this framework using structural equation modelling with a sample of 3,211 collected from light rail transit stations in Seville, Spain.Chen (2016) presents an extension of the structural equation modeling to hierarchical linear modeling and investigates the interrelationships between service quality, customer satisfaction, and behavioral intentions of bus passengers. De Ona et al. (2014) use classification and regression trees for quantifying the influence of the quality characteristics on overall service.

A vast literature exists on the evaluation of public transport performance and traveler satisfaction. As cities and distances to be traveled grow larger, the multimodal travels become more frequent. Thus, the assessment of service performance and travel experience in multimodal passenger transportation systems has gained more importance for designing sustainable transportation systems. The high percentage of multi-modal travels in metropolitan areas shows that the intermodal travels should not be disregarded when 
assessing the transportation systems. The drivers of the traveler satisfaction and the level of dependency of traveler satisfaction on these drivers need to be investigated and analyzed by the service planner for effective decision-making. To this aim, we offer the BBN methodology to assess multimodal transportation systems.

\section{Methodology}

Drawing on the previous literature, we analyze the factors influencing travelers' choices of access to rail transit stations and satisfaction with rail rapid transit systems in relation to these factors and their interrelationships. We then quantify these relationships and demonstrate the complexity of evaluating the performance of transit services. For this purpose, we employ a six-stage methodology (Fig.1).

\begin{tabular}{|l|l|l|}
\hline $\begin{array}{l}\text { Stage 1: Developing a } \\
\text { conceptual model }\end{array}$ & $\begin{array}{l}\text { Stage 4: Specification of the } \\
\text { causal map }\end{array}$ \\
$\begin{array}{l}\text { Reviewing the literature to identify } \\
\text { factors of interest }\end{array}$ & $\begin{array}{l}\text { Conducting expert interviews } \\
\text { Developing causal maps } \\
\text { Refining causal maps }\end{array}$ \\
\hline \begin{tabular}{l|l|} 
Stage 2: Data collection \\
Determining survey questions
\end{tabular} \\
\begin{tabular}{|l|l|} 
Applying the survey \\
Stage 3: Selection of the \\
variables
\end{tabular} \\
\begin{tabular}{|l|l|} 
Identifying hypothesis variables \\
using factor analysis
\end{tabular} \\
$\begin{array}{l}\text { Identifying information variables } \\
\text { via literature review }\end{array}$ & $\begin{array}{l}\text { Bayesian Belief Network } \\
\text { Improving the network structure using data } \\
\text { Calculating the conditional probabilities }\end{array}$ \\
\hline
\end{tabular}

Fig.1.The proposed methodology.

In the first stage, we develop the conceptual model of the BBN. We collect the data based on this conceptual model in the second stage, which comprises determination of survey 
questions, design of the survey, and implementation of the survey. In the third stage, we determine the variables that affect satisfaction using factor analysis. We also deduct the travel and traveler characteristics and the service performance criteria, which are the information variables in the $\mathrm{BBN}$, from an extensive literature review. In the fourth stage, we develop a causal map of the variables through expert interviews and refine the causal map to eliminate the relationships that result in cycles, as we need a directed acyclic graph in a BBN. In the fifth stage, we quantify the variables and transform the causal map into a BBN that represents the conditional dependencies and the uncertainties of these variables. In the sixth stage, we use the BBN as decision support tool to improve traveler satisfaction with rapid rail services. We then perform sensitivity analysis to determine the most critical variables that affect traveler satisfaction in public transportation. We test this methodology with the case of Istanbul Metro.

We employ a causal map to capture the expertise and the assumptions about the public transport system and to understand this system's behavior better becausecausal maps represent domain knowledge in the form of directed cause-effect relationships between variables in a more effective way than alternative models such as regression and structural equations (Nadkarni and Shenoy, 2001). BBN's effectiveness over alternative methods also originates from its ability to make inferences, i.e. drawing conclusions based on a premise (Nadkarni and Shenoy, 2001). Hence, BBNs enable adding new information to the system and allow for making predictions in the case of interventions. For example, an urban transport policy maker may want to know how access mode affects travelers' satisfaction and design policies targeted at specific modes.

In fact, soft systems approaches such as causal maps were designed to address complex problem situations, such as the traveler satisfaction with rapid rail systems that are unstructured and affected by human factors (Daellenbach and McNickle, 2005). The 
advantages of BBNs over existing methods in the analysis of complex systems and the relationships between the variables have made them attractive tools for analysis (Arentze and Timmermans, 2005; KocabasandDragicevic, 2007). We start with an effort to understand the complexity associated with traveler satisfaction in the public transportation domain (Ackermann, 2012). We then use expert judgments that are useful to structure the problems, to indicate key variables, and to examine the relationships among the variables (Morgan 2005).

In a causal map, nodes represent causal concepts, links represent causal connections, and strengths represent causal value of a connection. Different methods are used to construct causal maps, depending on the purpose and the theory guiding the research. Axelrod (1976) devise a mapping technique to represent the causal assertions embedded in decision-makers' argumentations about policy-making and decision-making. In another approach, Eden and Ackermann (1998) propose to use a deliberately open structure for interviewing. In this research, we useliterature review to elicit the concepts associated with travelers' satisfaction of rapid rail systems. We identify thecausal relations through interviews with practitioners and academicswhoare experts in the public transportation domain. We present these experts in Section 4.4 .

Once we identifythe concepts related to public transportation, we translatethem into variables considering their impact on the system. Hence,we specifythe variables of the public transportation system. Following the specifications of variables, we discuss theinterrelationsamongthese variables again with the domain experts and based on the feedback we specifycausal relations between the variables.

Causal maps are the initial stage of analysis to construct BBNs (Jensen 2001). A BBN is a directed causal network that is decision-focused, data-driven and transparent (Williams and Cole 2013). Although the relations represented in a BBN do not have to be causal, this 
research makes use of causal maps in the problem-structuring phase to reduce the problems encountered in specifying both the key variables and their causal relationships (Nadkarni andShenoy, 2004).BBNs are thus also causal belief networks where the dependence relations between variables are causal.In the BBN, nodes represent the variables of the system, and arcs directed from the parent (affecting) variable to the child (affected) variable represent the causal relations among the variables. To construct a BBN, initially, we define a finite set of states for each variable in the causal map. This set represents the possible behaviors that a variable can exhibit. We need both historical data and the subjective evaluation of experts for this purpose.

In the BBN methodology, we calculate the joint probability distributions of all variables in the network as the multiplication of conditional dependencies for each variable. The chain rule follows that $P(A, B, C)=P(A) \times P(B \backslash A) \times P(C \backslash B)$ if variable $A$ is serially connected to variable $C$ through variable $B$. This equation means, the probability of events $A$, $B$ and $C$ happening at the same time is calculated by multiplying the probability of event $A$ happening with the probability of event $B$ happening given that event $A$ has already happened and the probability of event $C$ happening given that event $B$ has already happened. We compute the posterior marginal probability of a variable from the jointprobability as $P\left(A_{i} \mid B\right)=\left[P\left(A_{i}\right) P\left(B \mid A_{i}\right)\right] /\left[P\left(A_{1}\right) P\left(B \mid A_{1}\right)+\cdots+P\left(A_{n}\right) P\left(B \mid A_{n}\right)\right]$.This equation is the famous Bayes' Theorem.

In the context of the $\mathrm{BBN}$, we conduct a sensitivity analysis to determine the relative importance of the variables in the system. Sensitivity analysis allows us to identify key variables that have higher impact on the values of the target variables, which are, in our case, measures of satisfaction. To verify our proposed methodology, we test it with data from the case of Istanbul Metro. 


\section{Case Study}

Istanbul has a population of approximately 14.6 million people, which has increased more than $10 \%$ in the last two decades (Celiket al.,2013). Almost ninety percent of transportation in Istanbul is by land-based transportation, $3.2 \%$ is by waterborne and $8.4 \%$ is by rail transportation (Celiket al.,2013). Every year approximately $10 \%$ increase is reported in the number of vehicles joining the traffic in Istanbul (Ozer and Kocaman, 2007). The growth of the city area and the traffic congestion due to the high number of private vehicles have caused $20 \%$ increase in the average travel time in the last decade, reaching 48 minutesfor all trips in the metropolitan area (Ozer and Kocaman, 2007). Table 1 shows the number of travelers and vehicle distributions for street, sea, and railway transportation (Celiket al.,2013).

Table 1.Distribution of street, sea and railway transportation in Istanbul.

\begin{tabular}{lrr}
\hline \multicolumn{1}{c}{ Type of Vehicle } & Fleet & Trips/day \\
\hline Buses & 5558 & $1,725,000$ \\
Metrobuses (BRT) & 334 & 715,000 \\
Employeeshuttles & 36,902 & $2,419,000$ \\
Private cars & $1,602,730$ & $2,800,000$ \\
Minibuses & 5,860 & $2,000,000$ \\
Taxis & 17,416 & 535,000 \\
Waterborne & 491 & 410,000 \\
Light Metro & 126 & 390,000 \\
Tramcars\&Funicular & 78 & 323,600 \\
Metro & 46 & 225,000 \\
Trains & 58 & 141,000 \\
\hline
\end{tabular}

In Istanbul, four local organizations coordinated by a central authority (Istanbul Metropolitan Municipality) manage public transportation. Istanbul Establishment of Electricity, Street Trams and Tunnel (IETT) is the largest and the first local organizationwhichcontrols the streetleveltransportation.IstanbulUlasim is the second company established tocontrol the metro and the light rail transportation. Two organizations are in charge of the sea transportation:Istanbul Fast Ferries Co. (IDO) and Istanbul SehirHatlariTurizmveTic. San.AS. Taxis, minibuses, private motorboats, and public buses carry a highpercentage (more than 50\%) of travelers. Public transportation services are used 
in $71 \%$ of the 15 million journeys made every working day in the metropolitan area(Özer and Kocaman, 2007). Even though a high percentage of multimodal transit travels takes place, the performance of services is analyzed individually. Considering the interaction among different services, there is a need to investigate the performance andthetraveler satisfaction for recognizing problems and service improvement areas in a multimodal context. For this purpose, we aim to learn the nature of relationships among a high number of factors affecting travel satisfaction; such as system characteristics, service performance indicators, travelerspecific factors, and exogenous factors in a network structure.

We apply our approach to one of the metro lines in Istanbul, M2, which operates with 11 stations in a highly populated business district in the city center (See Fig.2). The departure stations examined in the case study are marked with red rectangles in the public transport map given in Fig.2.The light yellow line passing from Topkapı - BayrampaşaMaltepe Edirnekapı - Şehitlik - AyvansarayEyüp - DarülacazePerpa - OkmeydanıHastane Çağlayan - Mecidiyeköy - Zincirlikuyu is the bus rapid transit (BRT) line.A high quality full map can be found on http://www.metro.istanbul/media/76013/istanbul-ulaisim-ag-haritasi.jpg. 


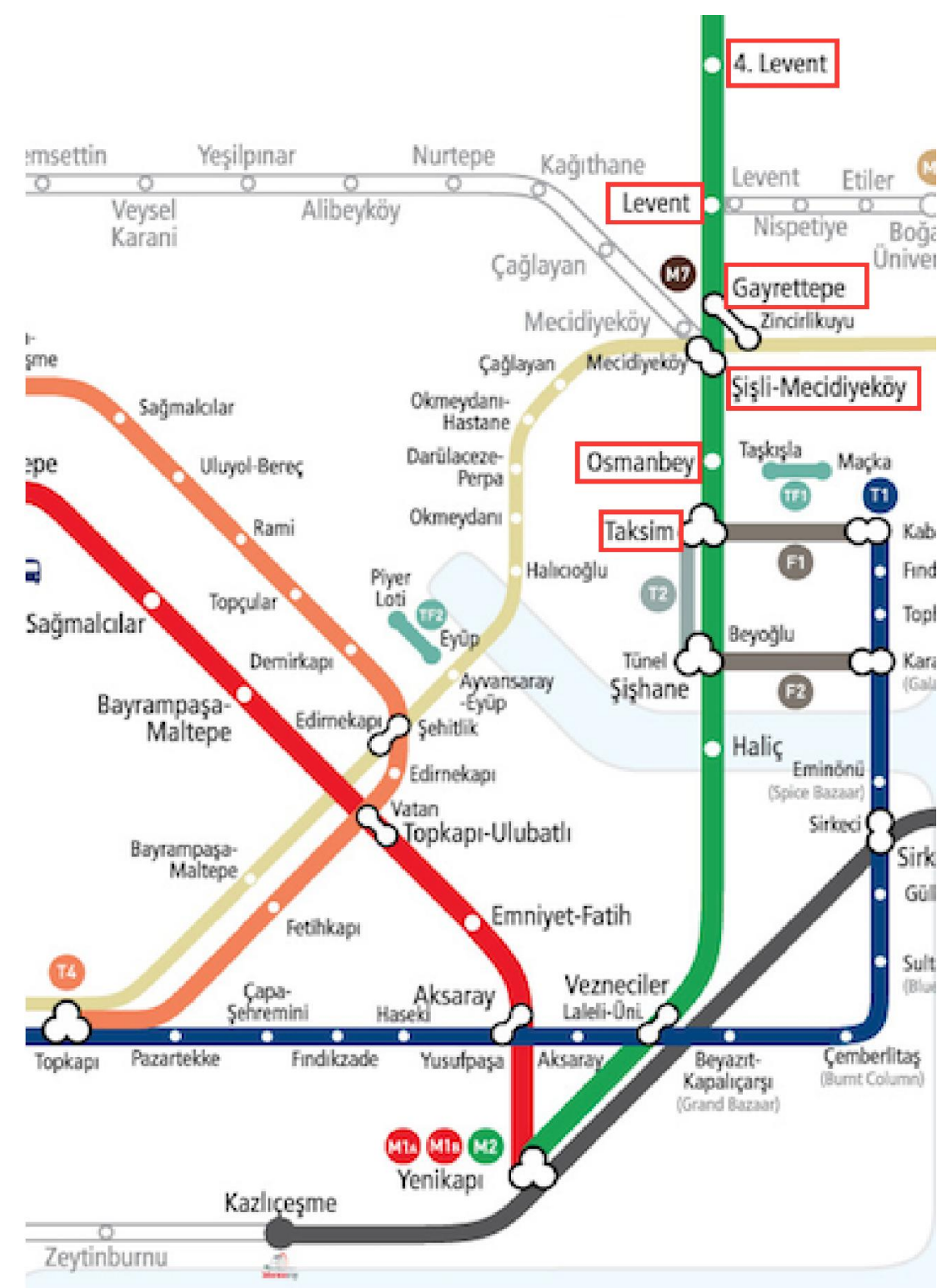

Fig.2.Case study: M2 line.

In a typical working day, at least $60 \%$ of the journeys made by $\mathrm{M} 2$ are multimodal transit journeys including at least one transfer between the metro and a connecting line of another mode. The performance of the integrated services including a metro trip and the number of travelers attracted by metro depends highly on the services of its connecting modes. Fifty fivepercentof the transit travels are connections from bus lines, $30 \%$ from the Bus Rapid Transit (BRT) line, 10\% from minibuses and 5\% from the funicular line. The connections of the transit travels are concentrated in three stations, which have the highest traffic (about 100,000 travelers per day)of all stations. The connections in these stations, which 
are Sisli, Taksim, and Levent, constitute approximately $63 \%$ of the connections of the metro transit travels (Ugurlu, 2011).

\subsection{Conceptual Model}

In this study, we investigate the interrelationships among the traveler satisfaction, travel/traveler characteristics and the service performance in a multimodal network in Istanbul. We illustrate the conceptual model derived from the literature in Fig.3.

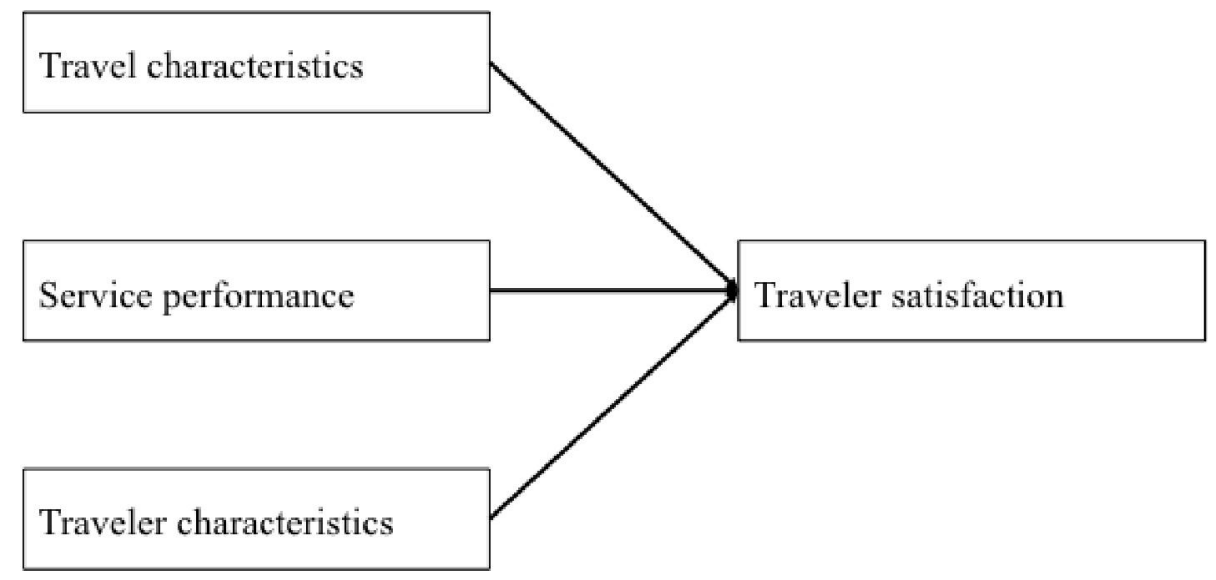

Fig.3. Conceptual Model of Traveler Satisfaction

We represent the three input dimensions as variables in the proposed BBN. We aim to identify the direct and indirect conditional dependencies between the variables using the network structure of the proposed methodology. In this method, we model the relationships among the variables in a network structure that allows inferences of the sequential effects in the whole system. Thus, the final network enables us to analyze the outcomes by changing the states of the variables of the system.

\subsection{Data Collection}

We obtained the data set from Istanbul Ulasim AS. It comprises a traveler satisfaction survey collected in January - February2010. Seven hundred and fifty participants answered the survey in11 stations of the M2line.For that purpose, Istanbul Ulasim AS employed a stratified sampling plan based on the number of travelers using each station. The survey participants were the randomly selected passengers in each station. In Table2, a summary of 
the sample statistics is given. The data set included information regarding the access part of the transit travels but not the egress part because the transport authority focused on accessibility at the time of the research. Consequently, we characterizethemultimodal transit travels with two variables, mode used for accessing the metro station ('access mode') and the departure metro station ('departure station').

Table2.Summary of theSampleStatistics

\begin{tabular}{|c|c|c|c|}
\hline \multicolumn{2}{|l|}{ Purpose of thetrip } & \multicolumn{2}{|l|}{ Age Range } \\
\hline Work / commuting & $33 \%$ & $14-25$ & $48 \%$ \\
\hline School commuting & $22 \%$ & $26-35$ & $32 \%$ \\
\hline Business trip & $27 \%$ & $36-45$ & $10 \%$ \\
\hline Other & $19 \%$ & $45-55$ & $5 \%$ \\
\hline \multicolumn{2}{|l|}{ Car Ownership } & $56+$ & $5 \%$ \\
\hline Yes & $34 \%$ & \multicolumn{2}{|l|}{ IncomeRange } \\
\hline No & $66 \%$ & $<1000 \mathrm{TL}$ & $21 \%$ \\
\hline Gender & & $1001-2000 \mathrm{TL}$ & $56 \%$ \\
\hline Male & $88 \%$ & 2001-3000 TL & $12 \%$ \\
\hline Female & $12 \%$ & $>3001 \mathrm{TL}$ & $7 \%$ \\
\hline
\end{tabular}

We specify the data related to access travel time and the total travel time of travelers based on the reports of the travelers on the survey questions. The survey was held at the stations of the M2 line while the passengers were leaving the station(e.g. How long did it take you to arrive at the M2 line? How long did it take you to travel on the M2 line?). The data set included exogenous factors that would affect the service offered to the traveler. The time of day of the traveland the type of ticket used for the travel werealso available for each traveler. We specify the spatial separation of the origin of the traveler and the station based on the location information provided in the data set. The data set also incorporatesdemographic informationof the travelers(gender, level of income, etc.) and the traveler satisfaction ratingsof the them. We use a disaggregate data set which includes categorical, numerical, and ordinal variables. The BBN methodology allows us to use data that are not always comparable by specifying representative states of the data (Pradhan et al. 1996; Heckerman 1997). 


\subsection{Selection of Variables}

In this study, we analyze the multimodal transit travels from the traveler's perspective. This point of view is acquired by including travel characteristics, service performance, traveler characteristics, and traveler satisfaction in the analysis of multimodal travels. We investigate the points that have been overlooked in previous public transportation research (Kim et al., 2017), such as attribute-based satisfaction and the relationship between the level of service and satisfaction.

We use the traveler satisfaction ratings in the survey to extract main satisfaction dimensions. We conduct a factor analysis to identify the main dimensions of traveler satisfaction from a high number of satisfaction questions. We apply anexploratory factor analysis to construct compact variables from highlycorrelated input variables. In other words, we use the exploratory factor analysis to elicit the four constructs related to service quality: Travel Time, Accessibility, Safety \& Security, and Comfort. This approach decreases the number of variables and hence the complexity of the causal map in the further analysis with the experts.Moreover,BBNs have a challenge when modeling variables that are correlated. They become densely connected and inference is then computationally intractable as the number of variables increases (Bensi et al., 2011). As can be seen in Table 3, these factors represent meaningful indicators with acceptable loadings. To incorporate these factors (Travel Time, Accessibility, Safety \& Security, and Comfort) into the Bayesian Belief Network, we use factor scores calculated from the analysis (see Section 4.4 for details).

Four factors that we name as travel time, accessibility, safety and security, and comfort explain $63 \%$ of the variance in traveler satisfaction. Table 3 shows the satisfaction questions and the factor loadings obtained from travelers' ratings. The negative values show a negative correlation between the related variables (rows) and the related factors (columns). 
Table 3.Exploratory factor analysis results*.

\begin{tabular}{lcccc}
\hline & \multicolumn{3}{c}{ Service Quality Dimensions } \\
\cline { 2 - 5 } \multicolumn{1}{c}{ Satisfaction Questions } & $\begin{array}{c}\text { Travel } \\
\text { Time }\end{array}$ & $\begin{array}{c}\text { Accessibil } \\
\text { ity }\end{array}$ & $\begin{array}{c}\text { Safety\&Secur } \\
\text { ity }\end{array}$ & Comfort \\
\hline Consistency to the declared time plans & 0.72 & & \\
Travel time & 0.68 & & \\
Waiting time & & -0.86 & \\
Access to the station & & -0.73 & 0.86 & \\
The safety \&security level in the station & & & 0.85 & \\
The safety \& security level in the vehicles & 0.71 & & & -0.81 \\
The manner \& attitudes of the security & 0.62 & & -0.73 \\
The cleanliness of the vehicles & & & \\
The air conditioning in the vehicles & & & \\
The level of crowding in the vehicles & & & \\
* Factor loadings less than 0.40 are suppresed & & & \\
\hline
\end{tabular}

* Factor loadings less than 0.40 are suppressed.

We represent the travelers' satisfaction by these four service quality dimensions.

'Travel time' as a service quality dimension represent the travelers' perception of the travel time and consistency of vehicles to the time plan. We identify 'accessibility' as a service quality dimension related to the ease of access to the metro station and waiting time of the traveler. 'Safety and security'dimension involves the security perception of travelers against crime in the stations and vehicles as well as safety perceptions related to accidents.Finally, 'comfort' includes the traveler satisfaction level related to crowding and air conditioning in the vehicles.

Then, we identifytravel characteristics as the variable of spatial separation of origin, access mode, and departure station. These variables represent the access connections of the multimodal transit travels. Besides, different access modes and the departure stationsprovidedifferent service characteristics for the travelers based on the technology, capacity, design, amenities, connections, average level of use, operations control strategies, etc.In our analysis, we specifyall modes connecting to the metro as the access modes, which arewalking, bus, bus rapid transit, funicular, minibus, taxi, and private car. Departure stations arethe sixstations that were in operation for the past 14years. These stations are Taksim, 
Osmanbey, Şişli, Gayrettepe, Levent, and DörtLevent. The remaining five stations have started to operate a couple of months before the survey wasconducted and they made travels that started from these stations necessitate a transfer temporarily at DörtLevent station. In thistransition period, data related to these stations yielded low levels of use as well as bias due to inconvenient service conditions. Therefore, we choose not to include these stations in the analysis.

The spatial separation of the origin to the departure station is an important factor for travelers in choosing which access mode and departure stationto patronize (Bates 2000; Lindsey et al. 2010). For example, travelers accept to walk, on average, 400 meters for accessing a bus service and 800 meters for accessing a rail transit service, otherwise they prefer to access these services by another mechanized transportation mode or not to access the services at all(Murray, 2001; O’Sullivan and Morall, 1996; Lam and Morall, 1982). In our analysis, the available data regarding the origin of the travelers is at the level of sub-districts. Therefore, the exact spatial separation of the origin and the departure station cannot be determined, but only an interval related to the distances may be calculated. Using the uncertain informationof the spatial separation, we categorize the origins, which are in subdistrictsintersecting with the metro lines 'close-by'and the rest as 'distant' origins.

There also exist other travel characteristics that are exogenous factors. For example, 'time of day' is a significant factor that represents the level of demand for the transportation services and the traffic situation during different hours of the day (Small et al. 2005; Burris and Pendyala 2002; Bowman and Ben-Akiva 2001; Bates et al. 2001; Noland and Small 1995). Even though the demand levels for specific services are mainly stochastic in nature, it is typical that transportation demand is higher during the peak hours in the morning and the evening.The high level of demand concentrated in a short period affects the service levels. On the other hand, service levels are also significantly different in the late nighttime of the day 
compared to the working hours of the day (Stathopoulos, \&Marcucci, 2014). To represent these implications, we have identified three states for the 'time of day' aspeak hours, non-peak hours, and late night. The level of service (e.g. frequency of the service) during late night periods is highly different from the peak and non-peak times of the day.

We identify'access travel time' and 'total travel time'variables as service performance measures of transit services. A main stream of research in transportation, choice modeling, most commonly make use of time and cost as the features for evaluating different travel alternatives(Brownstone and Small, 2005; Lyons and Urry, 2005;Hess et al., 2005; Lam and Small, 2001; Ben-Akiva et al., 1993). These studies show that travel time is generally the most important transportation service feature for travelers. To point out the value of different times of travel, we incorporateaccess time and total travel time inthe analysisseparately.

We also includetraveler characteristics commonly used in the literature such as gender, level of income, car availability, and ticket type in our analysis to represent different expectations and needs of different customer groups.Gender is included to observe the differences among male and female travelers. Level of income is included to reflect the priorities of different traveler groups with varying income levels. We specify three levels of income in the analysis. Car availability of the traveler is included to represent the effect of having a car as a travel alternative. We define 'car availability' in three states: the travelers that do not own a car, travelers that own a car but do not have car available for the travel, and travelers that have a car available for the travel. The variable 'ticket type' has also three states: regular ticket, the electronic transit pass, and monthly travel card.

\subsection{Specification of the Causal Maps}

The causal maps provide a visual representation of the concepts of a system. Table 4presents the variables of the causal map andcorresponding states of these variables. We determine the causal relationships between these variables via interviews with experts in the 
public transport domain. We ask three experts to specify the interrelationships among the variables. We chose the experts based on their knowledge and experience of public transportation. The experts who participated in our study are well recognized experts in the domain of transportation planning. One of the experts is an urban planner and presently works for Istanbul Metropolitan Planning Center. He is the chief of the department that prepares the transport master plan of Istanbul. The second expert is a civil engineer manager who is presently working on public transportation planning. He has extensive training on transport simulation programs and is responsible for simulation modelling. The third expert is a transportation professor at a recognized technical university of Turkey. His major research areas are systems engineering, transportation planning, and vehicle routing. He has led and participated in many transportation planning projects and published many academic papers. Although the number of experts who assisted us in this research may be considered low, all experts are highly competent, well informed, and skilled; besides they are eager to participate in our research. Our aim is to receive expert opinion of them on the problem at hand, rather than creating a representative sample of all experts on public transportation. This has been the case in similar studies (e.g. Poveda-Bautista et al., 2012; Oztaysi et al., 2011) where the same number of experts provided their judgment on the problem analyzed.

Table 4.Specification of the variables.

\begin{tabular}{ll}
\hline \multicolumn{1}{c}{ Variable } & States \\
\hline Travel time satisfaction & Satisfaction level related to travel time \\
Accessibility satisfaction & Satisfaction level related to accessibility \\
Safety \& security satisfaction & Satisfaction level related to safety \& security \\
Comfort satisfaction & Satisfaction level related to comfort \\
Access mode & Walking, bus, BRT, funicular, minibus, taxi, private \\
& vehicle \\
Departure station & Taksim, Osmanbey, Gayrettepe, Sisli, Levent, \\
& DortLevent \\
Spatial separation of origin & Close or distant \\
Time of day & Peak, Off peak, late night \\
Access time & Length of access time \\
Total travel time & Length of total travel time \\
Income level & Level of income \\
Gender & Female or Male
\end{tabular}




\begin{tabular}{ll}
\hline \multicolumn{1}{c}{ Variable } & States \\
\hline Car availability & No ownership, Owner but not available or Available \\
Ticket type & Regular ticket, Frequent traveler or Travel card \\
\hline
\end{tabular}

In the interviews, we ask the experts to compare the variables in a pairwise matrix and to specify whether a positive, negative, or no relation exists between each pair of variables. Since there are 14 variables, each expert did 91 pairwise comparisons. We obtain the final map through two revisions based on the feedback received from the experts. We prepare the resulting pairwise comparison matrix by aggregating the relationships based on the majority rule. Since the number of experts is odd, the majority rule ishelpful in addressing conflicting views about the types of relations (Nadkarni and Shenoy, 2004). We use a positive signed arrow between two variables if at least two of the experts suggest a positive relationship between two concepts. Figure 4 shows the resulting preliminary map. It is normal to have too many relationships drawn in the first causal map (Aktas, et al., 2007), because this is the stage we elicit the causal relationships for the first time. When the problem is analyzed for the first time, many cause-effect relationships are identified among the variables. However, to assist decision making, these relationships should be crystallized in the final causal map (Fig. 5) with the help of our experts' suggestions. 


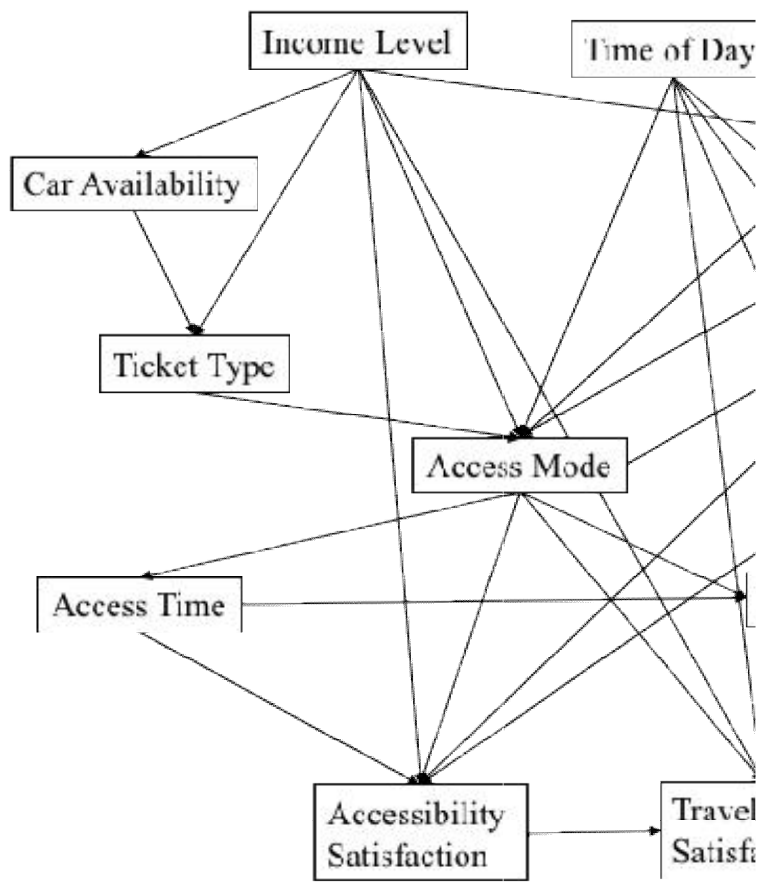

Fig.4. Preliminary causal map.

The identified causal relationships yield some variables that trigger the choice of access mode and departure station to be patronized. These variables aretraveler characteristics such as income level, car availability, gender, and ticket type; travel characteristics such as spatial separation and time of day. There arealso causal links between income level, car availability, and ticket type.

Access mode and departure station are key variables that show the elements of the systems patronized by the travelers. They are mainly affected by the independent variables (e.g. car availability, gender, spatial separation). On the other hand, these variables are the major determinants of the service performance indicators. Access time and total travel time variables that are defined as service performance indicators are affected by the access mode as well as the time of day and spatial separation. We identify variables related to different quality dimensions as a result of traveler perception as satisfaction indicators. These variables are affected by travel characteristics, traveler characteristics, and service performance factors (e.g. total travel time). Strong causal interrelationships are also identified among the 
satisfaction indicators. For example, travel time satisfaction is closely related to accessibility satisfaction.

The causal map presents the network structure required by the BBNs. BBNs are developed as directed acyclic graphical models which are defined with vertices and an adjacency relation of edges on the vertices. The required acyclic structure of BBNs does not allow any cycles that start at a vertex and follow a sequence of edges that loops back to the same vertex.

The initial causal map has cycles which need to be removed to maintain the acyclic structure of the BBN. For this purpose, we revise the causal map through additional interviews with the experts. In some other type of cases, the cycles may also be formed due to a dynamic relationship between concepts across multiple time frames. In such cases, a part of the edges of a loop belong a former time frame, whereas the others relate to a later time frame. To solve this problem, concepts are disaggregated into multi-timeframes. Besides, relationships between the concepts may be distinguished as direct and indirect relationships. We discuss the direct and indirect relationshipswith the experts and ask them to state the dominant causal influence when two concepts have reciprocal influences. As a result of these discussions, we conclude that multi-timeframes are not applicable to the BBN in this research. After several iterations and clarifying the cause and effect relationships between the factors that affect travel time satisfaction, we obtain the final map that is shown in Fig.5.

In the final causal map, the experts suggest that the critical variable is the travel time satisfaction because it is the main satisfaction indicator of the transportation service. The relations illustrated in the map treat travel time satisfaction as an overall satisfaction variable which is affected by the travel time related indicator (i.e. total travel time) as well as indicators of other satisfaction dimensions (i.e. comfort, safety\&security, and accessibility). 
As observed on the final map, access mode to the metro line M2 is the most important system variable whichis related to all variables of the network either directly or indirectly. Variables such as time of day, gender, spatial separation, ticket type, and car availability directly affectwhereasincome level indirectly affects the access mode. On the other hand, satisfaction indicators related to time and accessibility depend on the access mode. The departure station, where interchange takes place for multimodal travels, directlyaffectssatisfaction dimensions of comfort, accessibility, safety and security. The parent variables of the departure station are access mode and income level.

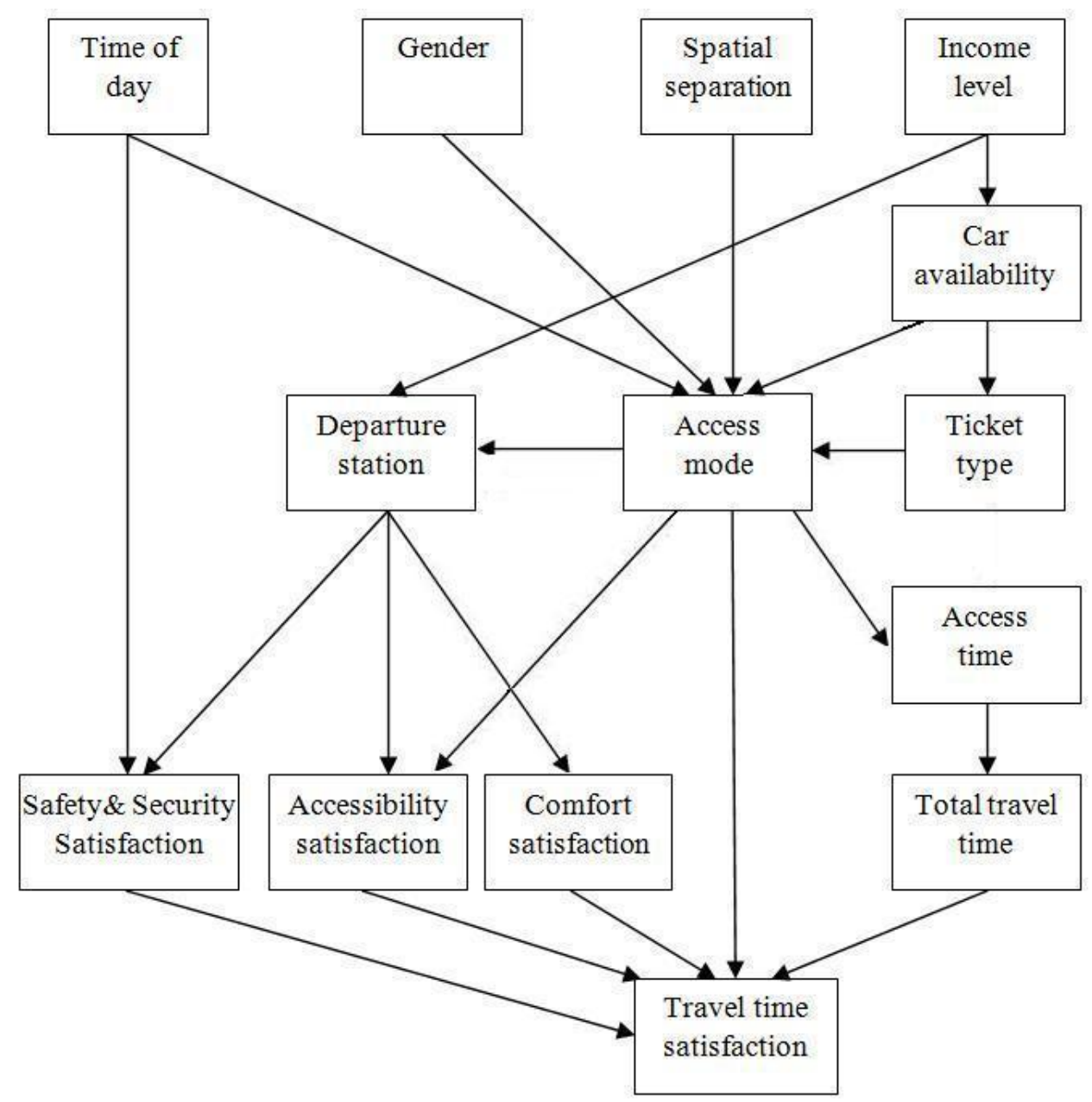

Fig.5.Final causal map.

\subsection{Construction of the Bayesian Belief Network}

Using causal maps, it is not possible to model the uncertainties associated with the decision variables and make inferences about the concepts. BBNs offer a probabilistic 
approach by identifying the concepts as random variables and causal relationships as conditional dependencies. To construct the BBN, we applytwo stages: first, we identify the states of the random variables. Then, we calculate the conditional probabilities of the variables in the BBN. Next two sub-sections present the procedure of these two stages.

\subsubsection{States of the variables}

The states of the categorical variables are based directly on the specification of variables as discussed in Section 4.3. However, the numerical variables such as travel time have been transformed into discrete variables before calculating the conditional probabilities. The discretization is made by considering breakpoints in the data (Aktas et al., 2007) as shown in Fig.6. For example, the states of access time are defined as short (less than 15 minutes), medium (between 15-50 minutes) and long (longer than 50 minutes). Similarly, total travel time is discretized as short (less than 25 minutes), medium (25-65 minutes) and long (longer than 65 minutes). Since the access time is a part of the total travel time, the state boundaries of the access time and total travel time are different.

Traveler satisfaction levels related to the service quality dimensions are specified as high, medium or low. Three discrete statesof the variables are specified by considering breakpoints in the data.In Fig.6, the first four graphsshow the sorted factor scores which are obtained from factor analysisand the number of respondents for each satisfaction dimension and the breakpoints on each graph. The latter two graphs of Fig.6 titled as access time and total travel time directly show the time in minutes and the number of respondents. 


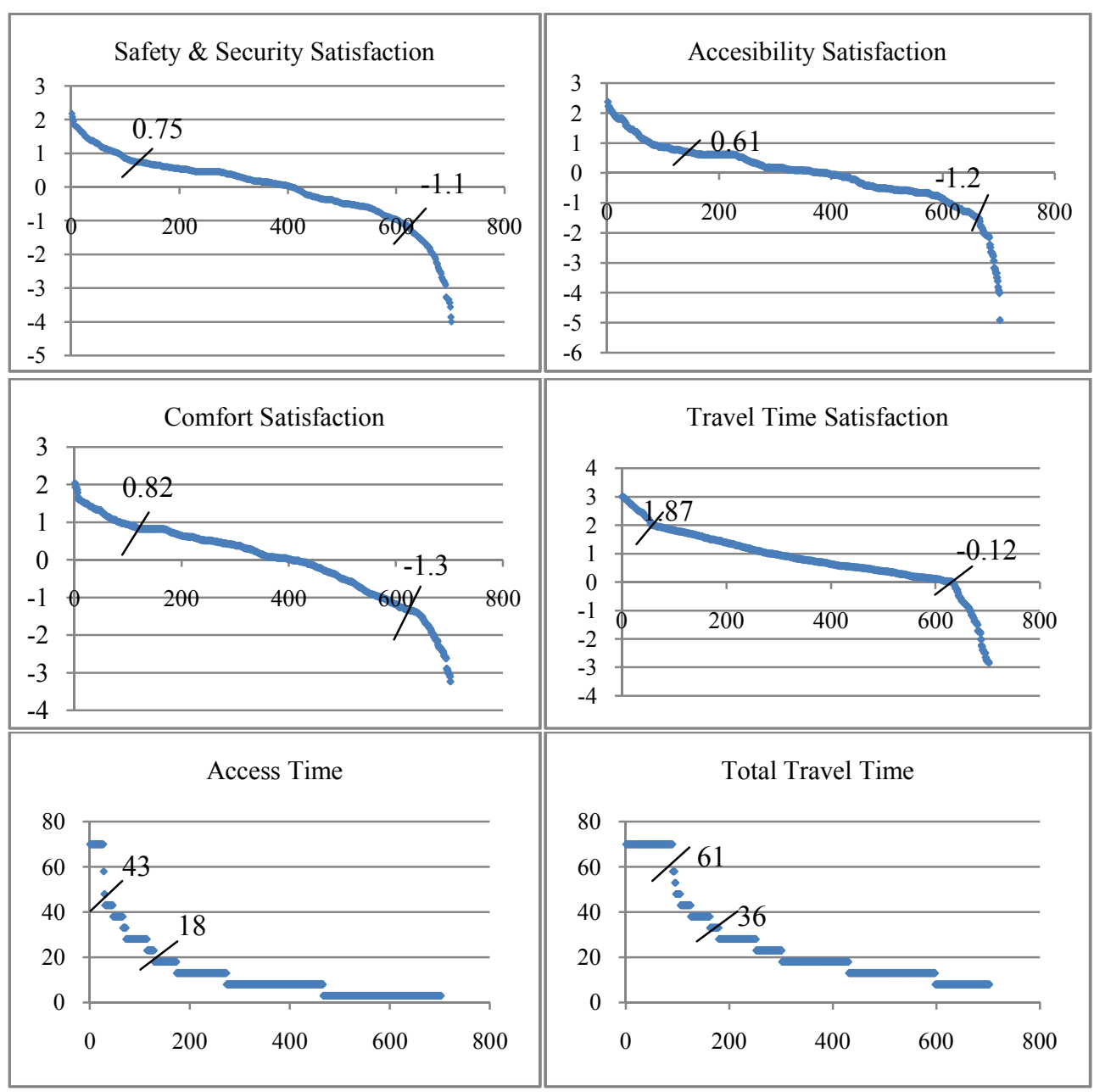

Fig.6.Discretization of the variables.

The states of the variables together with the number of nodes and links determine the number of conditional probabilities to be calculated. The final network yields 14 nodes, 20 links and 2,335 conditional probabilities in total.

\subsubsection{Conditional probabilities}

BBNs consist of a probability distribution for each node as represented by conditional dependencies captured with the directed acyclic graph. Each node in the network has an associated conditional probability table that describes the conditional probability distribution of the node given different assignments of the states of its parents. A conditional probability table $P\left(A \mid B_{1}, \ldots, B_{n}\right)$ has to be attached to each variable $A$ with parents $B_{1}, \ldots, B_{n}$. If $A$ has no parents, the table reduces to the marginal probability table $P(A)$ (Janssens et al., 2006). 
Wealso examine whether the network structure of the final causal map may further be simplified using the dataset. The final network structure is improved using the approach developed by Geiger et al. (1990). This approach proposes that if $X$ is independent of $Y$ given $Z$ for every value of $X, Y, Z$ say $x, y, z \operatorname{then} P(X=x \mid Z=z)=P(X=x \mid Z=z, Y=y)$. Namely, the probability of any value of $X$ given any value of $Z$ is not affected by any value of $Y$.

In the final BBN, the prior probabilities specified for the time of day, gender, spatial separation, and income level are marginal probabilities because these variables have no parents. Whereas, variables such as access mode, departure station, satisfaction dimensions, and others have parents, so conditional probabilities are specified. For example, the conditional probability defined for access mode is P(AccessMode|TimeofDay, Gender, SpatialSeperation, TicketType). According to Bayes' rule, this probability can be formulated as:

P(AccessmodelTimeofDay, Gender, Spatialseperation, TicketType) $=\mathrm{P}$ (AccessMode, TimeofDay, Gender, Spatialseperation, TicketType, Car availability) / P(TimeofDay, Gender, Spatialseperation, TicketType)

If the parent variables are independent, then the equation is reduced to: P(AccessmodelTimeofDay, Gender, Spatialseperation, TicketType $)=P($ AccessMode, TimeofDay, Gender, Spatialseperation, TicketType) / [P(TimeofDay) x P(Gender) x P(Spatialseperation) x P(TicketType) ]

The prior frequency distributions for the variables are derived from the data. Using the frequency distributions, conditional probabilities are calculated. When dependencies are specified for the sequences of variables, the computations of the probabilities get more 
complex. So, we use Neticav4.16 which provides a probabilistic inference algorithm for BBNs. The compiled final network and the calculated prior probabilities are given in Fig.7.In our dataset, the data is complete for all variables (no missing data or latent variable), so the learning method from cases is employed to derive the conditional probabilities. Learning from cases results in probability revision in the following manner: At each node, all conditional probabilities start as uniform. For each case to be learned; only nodes for which the case supplies a value (finding), and supplies values for all of its parents, have their conditional probabilities modified.

The survey data shows that $44.6 \%$ of travels are made during peak hours, $44.3 \%$ during off peak and $11.1 \%$ during late night hours. The gender of the travelers is $88 \%$ male and $12 \%$ female. The travelers' origin is a distant location with respect to the metro line with a probability of $6.87 \%$ and a close location with a probability of $93.1 \%$. The income level of the travelers is high with probability $11.4 \%$, medium with probability $87.3 \%$, and low with probability $1.27 \%$.

Similarly, the conditional probabilities for all variables which have parentsare calculated. The prior probabilities obtained for the access mode to the M2 metro line is as follows: $58 \%$ walking, $20 \%$ bus, $6 \%$ bus rapid transit(metrobus), funicular, private car and taxi 4\%, and minibus 3\%. The travels made by M2 depart from Şişli with 24\%, Taksim and DörtLevent 19\%, Osmanbey 18\%, Levent $14 \%$ and Gayrettepe 5\%. The prior probabilities for the satisfaction levels of M2 travelers regarding the services are given in Table 5.

Table 5.Beliefs for satisfaction levels of M2 travelers.

\begin{tabular}{llll}
\hline & High & Medium & Low \\
\hline Accessibility & $33 \%$ & $54 \%$ & $13 \%$ \\
Comfort & $23 \%$ & $65 \%$ & $13 \%$ \\
Safety \&Security & $17 \%$ & $68 \%$ & $15 \%$ \\
TravelTime & $19 \%$ & $63 \%$ & $19 \%$ \\
\hline
\end{tabular}




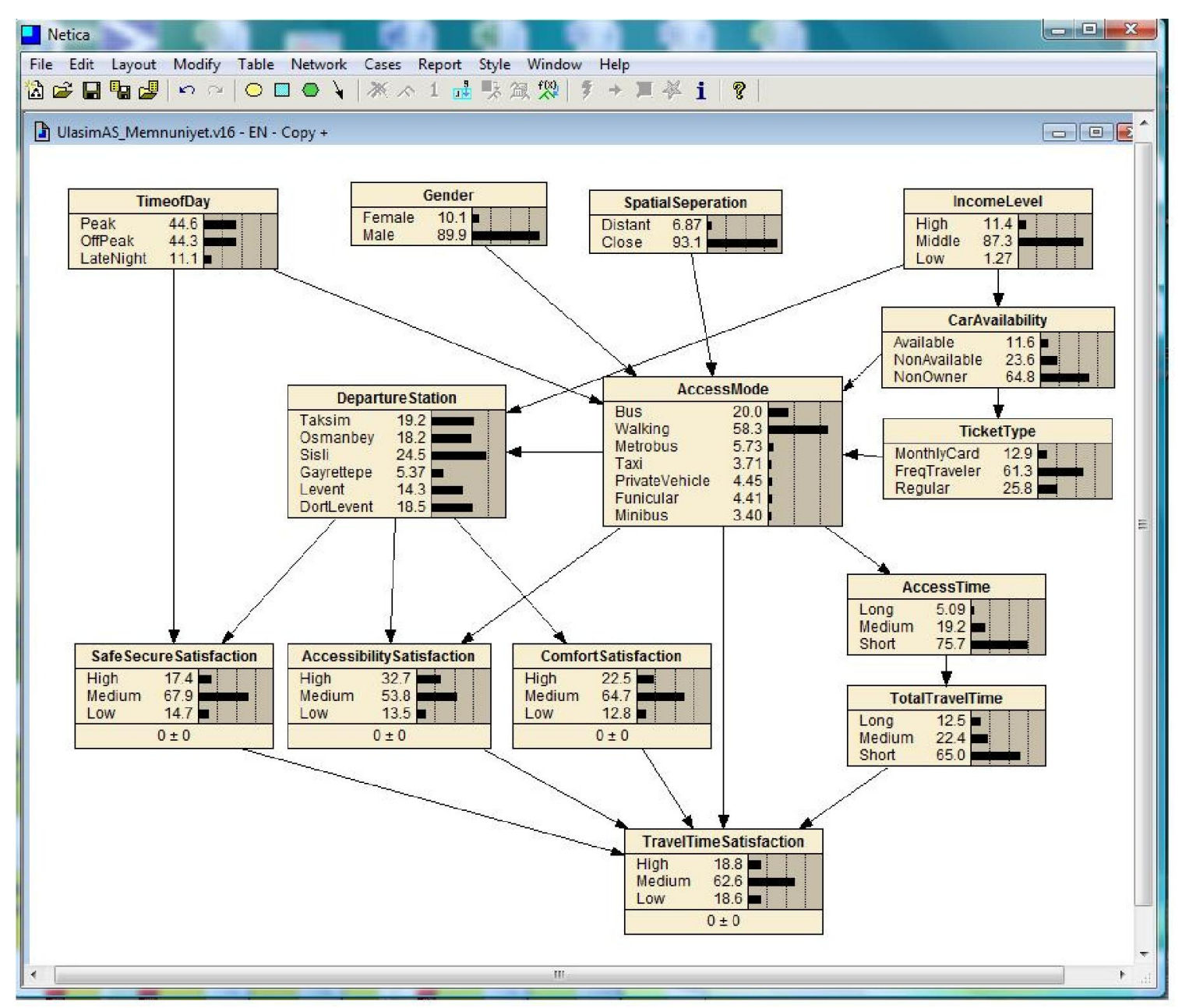

Fig.7.Compiled BBN.

\subsection{Decision Support for Policy Making}

Policy making in public transportation is challenging because it is expected to satisfy many criteria such as traveler satisfaction, system capabilities, and cost effectiveness. When the size of the transportation system grows, multi-modal travels which are mainly burdensome for the passengers need to be effectively incorporated into planning and decision-making. We present the $\mathrm{BBN}$ as an effective visualization and decision-support tool for the inference of the sequential effects in the transportation system including multi-modal travels and gain deep insight of the dependencies of the system.Next two sub-sections present the calculation of the posterior probabilities and the sensitivity analysis as tools to be used for decision support in public transportation policy making. 


\subsubsection{Posterior Probabilities}

The prior probability distributions given in Section 4.5are useful but more importantly BBNs compute posterior probability distributions of the variables, given that values of some other variables are known. For example, if we know the access mode of the traveler, we can find the posterior probabilities of satisfaction levels of performance dimensions.

For instance, if we know that the traveler's mode is bus, this additional information is represented as $\mathrm{P}^{\star}$ (AccessMode $=$ Bus; AccessMode $=$ Walking; AccessMode

= Metrobus; AccessMode = Taxi; AccessMode =PrivateVehicle; Accessmode = Funicular; AccessMode = Minibus) = $(1 ; 0 ; 0 ; 0 ; 0 ; 0 ; 0)$. The posterior probability $P^{*}$ is calculated as, P*(AccessMode, TimeofDay, Gender, Spatialseperation, TicketType) = P(TimeofDay, Gender, SpatialSeperation, TicketTypel AccessMode) $\mathrm{x}$ P*(Accessmode) $=$ [P(AccessMode, TimeofDay, Gender, SpatialSeperation, TicketType) x $P *($ AccessMode $)] / P($ AccessMode $)$.

The computation of this case on Netica is depicted in Figure 8. Using the posterior probabilities, predictions for different cases can be obtained. The travel time satisfaction levels for travelers accessing the M2 metro line with different modes is predicted as shown in Table 6.If we know the access mode of the traveler, we observe that the probability distribution does not change significantly for the access modes of bus and walking. For other access modes, the probability distribution changes significantly. This is the information that is insightful for policy making. 


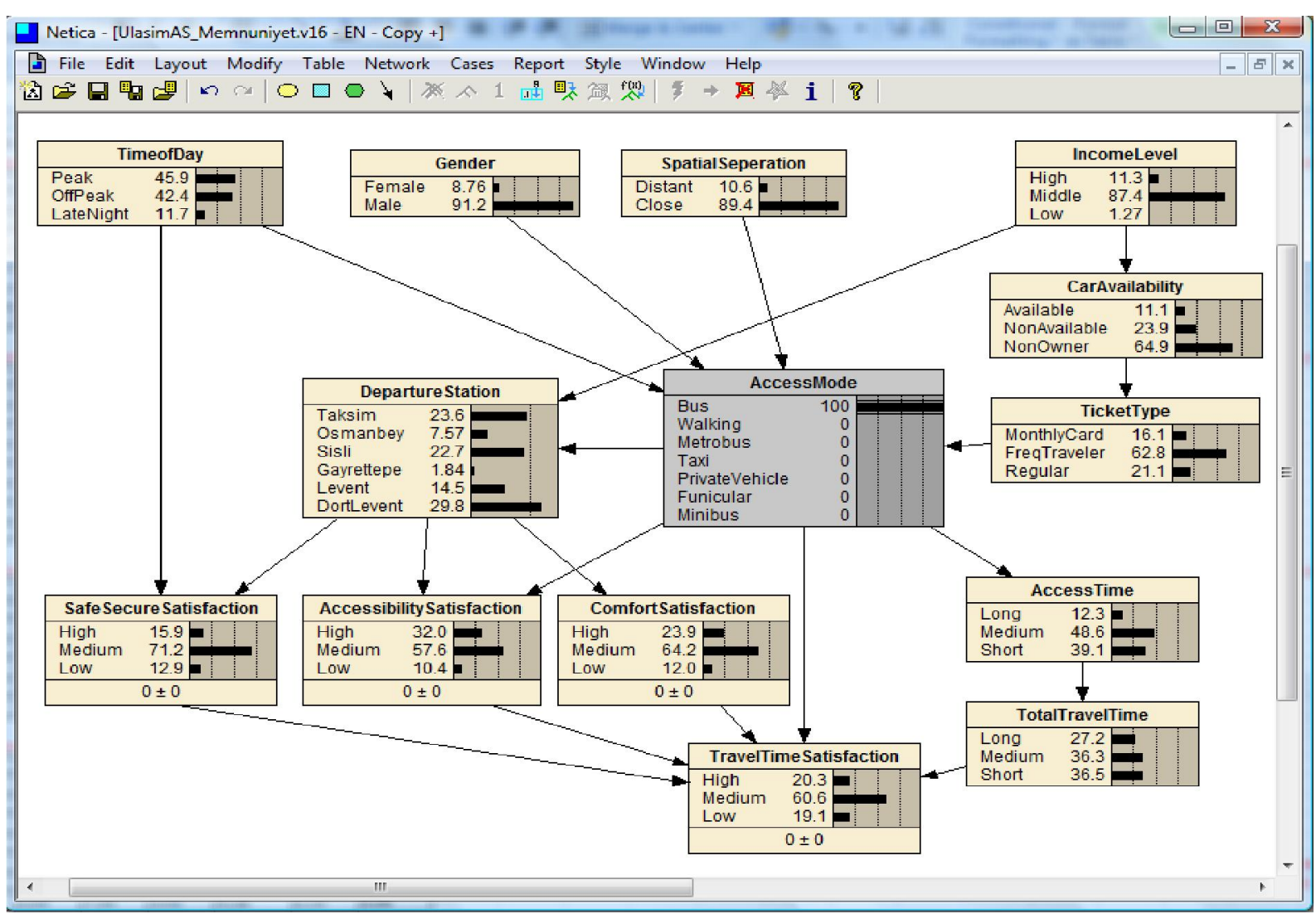

Fig.8.The case where 'access mode' is known.

Under each of these access modes, the travel time satisfaction is either higher or lower compared to the no information case. This shows two groups of access services in these types of modes. One of these offers a better service resulting in higher travel time satisfaction and the other offers poor service resulting lower travel time satisfaction.

Table 6.Posterior probability distribution of 'travel time satisfaction' when 'access mode' is known.

\begin{tabular}{lccc}
\hline & \multicolumn{3}{c}{ Travel Time Satisfaction } \\
\cline { 2 - 4 } & High & Medium & Low \\
\hline No additional Information & $18.8 \%$ & $62.6 \%$ & $18.6 \%$ \\
Access Mode Is Bus & $20.3 \%$ & $60.6 \%$ & $19.1 \%$ \\
Access Mode Is Walking & $14.0 \%$ & $71.6 \%$ & $14.3 \%$ \\
Access Mode Is Metrobus (BRT) & $31.2 \%$ & $39.2 \%$ & $29.7 \%$ \\
Access Mode Is Taxi & $29.1 \%$ & $41.9 \%$ & $29.1 \%$ \\
Access Mode Is Private Vehicle & $30.8 \%$ & $39.3 \%$ & $29.9 \%$ \\
Access Mode Is Funicular & $27.9 \%$ & $44.2 \%$ & $27.9 \%$ \\
Access Mode Is Minibus & $32.3 \%$ & $36.9 \%$ & $30.8 \%$ \\
\hline
\end{tabular}

We show another example of predicting posterior joint probabilities, which can also be computed when information on more than one variable is available.For example, posterior 
probabilities of access mode are observed when the accessibility satisfaction is low, access time is medium and travel time satisfaction is high. The prior probabilities and posterior probabilities are compared in Table 7. The evidence is that satisfaction level of travel time is high, accessibility is low and access time is medium.Under this evidence, the probability of traveler's arriving at M2 metro line by funicular and walking modes decrease. Thus, it may be concluded that access by funicular and walking modes endow travels with high accessibility and short travel time.

Table 7.Posterior probability distribution of 'access mode' under evidence.

\begin{tabular}{lcc}
\hline Access Mode & $\begin{array}{c}\text { Prior } \\
\text { Probabilities }\end{array}$ & $\begin{array}{c}\text { P*(AccessibilitySat.Low, } \\
\text { AccessTime } \\
\text { Travedium, } \\
\text { TravelimeSat.High) }\end{array}$ \\
\hline Bus & $20.0 \%$ & $33.2 \%$ \\
Walking & $58.3 \%$ & $10.5 \%$ \\
Metrobus (BRT) & $5.7 \%$ & $24.7 \%$ \\
Taxi & $3.7 \%$ & $10.4 \%$ \\
PrivateVehicle & $4.4 \%$ & $6.3 \%$ \\
Funicular & $4.4 \%$ & $3.8 \%$ \\
Minibus & $3.4 \%$ & $11.2 \%$ \\
\hline
\end{tabular}

\subsubsection{Sensitivity Analysis}

The developed BBN of the multimodal transportation system is used to analyze the complex conditional dependencies amongst the system's variables. The network's visual characteristic allows easy what-if and sensitivity analyses by simply changing variable states and observing the automatically updated decision outcomes. Travel time satisfaction is the main performance indicator and accepted by the experts to be the most critical variable in the system. So, sensitivity analysis was done to identify the relative importance of those variables affecting travel time satisfaction, which are total travel time, access mode, accessibility satisfaction, comfort satisfaction, safetyand security satisfaction.

The value describing the degree of sensitivity of one node to another is given in the 'Mutual Info' column of Table 8. For continuous nodes, or nodes with state values defined, 
this column corresponds to the variance reduction; otherwise, it represents entropy reduction. The 'Mutual Info' shows how much the variable can affect the query node (travel time satisfaction) due to a finding of another variable named as varying variable. The higher the mutual info sensitivity measure is, the more effective has the parent (varying) variable.

The 'Quadratic Score' column is a measure of distance between target and approximations. Basically, the scoring reflects how much information is obtained from observing an event with probability $P$. The more the information (and the quadratic score of parent variables) is available, the more sensitive is travel time satisfaction to that variable. The 'Quadratic Score' compares the sensitivities to the findings in each node. Travel time satisfaction is most sensitive to accessibility satisfaction and access mode, followed by total travel time, safetyand security satisfaction, and comfort satisfaction.

Table 8. Sensitivity of 'travel time satisfaction' based on findings at another node.

\begin{tabular}{lcc}
\hline Node & Mutual Info & Quadratic Score \\
\hline Accessibility satisfaction & 0.05479 & 0.0103149 \\
Access mode & 0.04759 & 0.009749 \\
Total travel time & 0.01967 & 0.0042372 \\
Safetyand security satisfaction & 0.01699 & 0.0036876 \\
Comfort satisfaction & 0.00981 & 0.0021108 \\
\hline
\end{tabular}

In the literature, the importance of accessibility has been investigated extensively. In unimodal travels, the accessibility is specified as the walking time or distance to the transportation service. Acceptable access distances and the percentage of the population covered accordingly have been specified for certain geographies (Murray, 2001; Danaher, 2003). In case of multimodal transportation, accessibility is a former part of the travel, commonly aservice with less capacity in a chain of interconnected travels. Then, the travel time contains various types of components such as walking time, access time, transfer time, waiting time, search time, delay time. Pratt (2000) has identified the importance of these components relatively. His study suggests that the most important component of travel time is 
accessibility when there is no delay in a travel with a transfer, which is in line with the findings of our study as well.

An earlier version of this survey is used in the study of Celik et al. (2013) to evaluate and improve customer satisfaction in Istanbul public transportation. They identify the priority sequence of public transportation firms through a fuzzy multi-criteria decision model. Different from our study, they suggest the decision makers to take action to reduce the intensity of passengers at bus stops. That is mainly due to the nature of the data they use, where travelers using bus services participated in the survey.

A complementary work by Zheng and Geroliminis (2013) investigate space distributions in a multimodal network and the effects of interactions among modes on network traffic performance. They find that policy makers face a trade-off between the operational cost of bus lanes and the savings in passenger hours travelled and it is not always efficient to give space to bus lanes. They recommend using dynamic pricing to shift demand between modes to improve the network performance. However, the effect of such a policy on traveler satisfaction is yet to be investigated.

In summary, we first identify the structure of the network (the variables and the relationships among them) using expert opinion. Once the structure is set, we determine the states of the variables and use an empirical dataset for specifying the conditional probability tables of each variable as is commonly named the learning of the Bayesian networks. Then, the $\mathrm{BBN}$ becomes ready for making probabilistic inference by implying any given evidence(s) and observing the posterior probabilities. Another type of analysis that is conducted with the BBNs is sensitivity analysis. Sensitivity analysis identifies the variable which affects the selected query variable the most.

We limit the use of the dataset to the learning of conditional probabilities. However, the structure of the network can also be identified by using advanced algorithms and an 
extended dataset. In this study, we employ an approach incorporating expert opinionsinto identifying the structure (i.e. relationships of the network).

In our network, we only have decision nodes so the states of the variables must be discrete to employ the BBN approach. Thus, we discretize the variables by introducing cut-off points based on the slope changes of the partial relations. However, a more structured algorithm which identifies the cut-off points by learning from the cases may be introduced.

In our problem, we have no missing values in our dataset, neither a latent variable in our network. Thus, learning of the conditional probabilities is straightforward. In case of missing data and latent variables, more advanced algorithms are required for the learning of the conditional probabilities.

\subsection{Limitations}

In BBNs, model selection is based on the likelihood that considers parameter variability for fixed sample values and no significance testing is performed when using this approach to model selection. Bayesian procedure is usually more robust to false associations due to the use of prior probability distributions that can tune the level of evidence needed to accept an association (Sebastiani and Perls, 2008). So, the model is more probable than the model of stochastic independence, given the data.

One of the major limitations of BBNs is computational complexity. BBN algorithms are of non-polynomial complexity, which means that the computation time grows exponentially as the network complexity grows.

\section{Conclusion}

In this study, we usea BBN approach for performance evaluation of multimodal transportation systems. The integrated services offered to travelers are difficult to evaluate due to the interaction among the incomparable variables and the stochastic nature of the 
system. Bayesian networks allow us to represent and visualize the system and to conceptualize the association between variables.

In the final $\mathrm{BBN}$, which is developed to investigate the multimodal travels of trunkand-feeder systems, the most important variable of the multimodal travels is the access (feeder) mode. Since the trunk mode is a high capacity and high speed mode, the main performance determinant of the multimodal transportation systems is the performance of the feeder mode. Thus, feeder modes should be carefully planned and integrated to the trunk mode for effective multimodal transportation systems. Tyrinopoulos and Antoniou (2008) also report that most important factor obtained in factor analysis of satisfaction survey data is the one including accessibility and waiting conditions. The second important factor is transfer quality described by the distance and waiting time. Then, the service production attribute including the service frequency and on-time performance are listed.

Besides, in the case study, accessibility satisfaction and access mode variables are shown to be more effective variables than the total travel time for travel time satisfaction. This also indicates the importance of access in multimodal travels. The performance dimensions, comfort, safetyand security, and accessibility are found to be closely related to departure station of the trunk line which is the interchange station for multimodal travels.Debrezion et al. (2009) also statethat easily accessible railway stations are more likely to be patronized as departure stations than less accessible stations. They assert that the availability of other access modes such as car, public transport, and the quality of the stationare expected to influence the choice of a departure railway station.

To the best of our knowledge, the use of BBN methodology in the framework of traveler satisfaction and service performance isproposed for the first time in the literature in this paper. Artificial intelligence techniques which are based on learning from data allow researchers to model non-linear relationships under uncertainty. The use of BBN to represent 
and model the relationships among traveler satisfaction and service performance offers a new avenue of research. In this framework, the BBN methodology could be further investigated to learn the network structure and probabilities using various algorithms proposed in the literature.

From the practitioner's point of view, BBN methodology offers visualization of the relationships to capture the dynamics of the system easily. As well, it is an effective tool to obtain the results of any change on the system via the network structure and the conditional probabilities. The proposed framework should act as a useful guide for transportation service providers and policy-makers in developing strategies to improve the performance of selected transportation systems, as well as in the allocation of scarce resources, subject to budget constraints and other system priorities.

A final point to highlight is that we do not capture the trips from the trunk end-point to final destination due to lack of data. This part of the journey may have an impact on the overall satisfaction and future work, if possible, should incorporate this aspect. We present an idea of using Bayesian Belief Networks to assist transport policies; however, our approach should be extended in terms of data and implementation steps to better support transport policy decisions. Future research may also investigate the differences resulting from the use of local vs. regional and national data sources to generalize the use of the proposed model. The service providers may comparatively be able to assess their service performance which will result in an alignment in the quality of the transportation systems and improvement in the quality of life.

\section{Acknowledgements}

We thank our editor Professor Wong and two anonymous reviewers for their careful review, constructive comments, and clear suggestions that have improved our paper to its final state. 


\section{References}

Ackermann, F. (2012). Problem structuring methods 'in the Dock': Arguing the case for Soft OR. European Journal of Operational Research, 219(3), 652-658.

Aktas, E, Ulengin, F., Şahin, Ş.Ö.(2007) A decision support system to improve the efficiency of resource allocation in healthcare management.Socio-Economic Planning Sciences, 41, 2, 130-146.

Arentze T. A., Timmermans H. J. P. (2005) Representing mental maps and cognitive learning in micro-simulation models of activity-travel choice dynamics, Transportation 32, 321-340.

Aydin, N., Celik, E., \&Gumus, A. T. (2015).A hierarchical customer satisfaction framework for evaluating rail transit systems of Istanbul. Transportation Research Part A: Policy and Practice, 77, 61-81.

Axelrod R. (1976) Structure of decision. Princeton, NJ: University of Princeton Press;.

Bates, J. (2000) History of demand modeling. In: Handbook of Transport Modelling, edited by D.A. Hensher and K.J. Button, Elsevier Science Ltd., Amsterdam, NH.

Bates, J., Polak, J., Jones, P., Cook, A. (2001) The valuation of reliability for personal travel. Transportation Research Part E, 37, 2-3, 191-229.

Ben-Akiva, M., Bolduc, D., Bradley, M (1993) Estimation of travel choice models with randomly distributed values of time. Transportation Research Record, 1413, 88-97.

Bensi, M., Der Kiureghian, A., \& Straub, D. (2011).Bayesian network modeling of correlated random variables drawn from a Gaussian random field.Structural Safety, 33(6), 317-332.

Bowman, J. L. and Ben-Akiva, M. E. (2001) Activity-based disaggregate travel demand model system with activity schedules. Transportation Research Part A, 35, 1, 1-28.

Brons, M., Givoni, M., Rietveld, P. (2009) Access to railway stations and its potential in increasing rail use. Transportation Research Part A, 43, 136-149.

Brownstone, D., Small, K.A. (2005) Valuing time and reliability: assessing the evidence from road pricing demonstrations. Transportation Research Part A, 39, 279-293.

Burris, M.W. and Pendyala, R.M. (2002) Discrete choice models of traveller participation in differential time of day pricing programs. Transport Policy, 9, 3, 241-251.

Carrel, A., Mishalani, R. G., Sengupta, R., \& Walker, J. L. (2016). In pursuit of the happy transit rider: dissecting satisfaction using daily surveys and tracking data. Journal of Intelligent Transportation Systems, 20(4), 345-362.

Cascetta, E., \&Cartenì, A. (2014). A quality-based approach to public transportation planning: theory and a case study. International Journal of Sustainable Transportation, 8(1), 84-106.

Celik, E., Bilisik, O. N., Erdogan, M., Gumus, A. T., \&Baracli, H. (2013).An integrated novel interval type-2 fuzzy MCDM method to improve customer satisfaction in public transportation for Istanbul. Transportation Research Part E: Logistics and Transportation Review, 58, 28-51.

Celik, E., Aydin, N., \&Gumus, A. T. (2014). A multiattribute customer satisfaction evaluation approach for rail transit network: A real case study for Istanbul, Turkey. Transport Policy, 36, 283-293.

Chen H.K. (2016) Structural interrelationships of group service quality, customer satisfaction, and behavioral intention for bus passengers. International Journal of Sustainable Transportation, 10( 5), 418-429.

Chen M.C. \& Wei, Y. (2011) Exploring time variants for short-term passenger flow.Journal of Transport Geography, 19( 4), 488-498. 
Chorus C.G., Arentze T.A., Timmermans H.J.P (2007) Information impact on quality of multimodal travel choices: conceptualizations and empirical analyses, Transportation 34, $625-645$.

Chou, J.S., Kim, C. (2009) A structural equation analysis of the QSL relationship with traveler riding experience on high speed rail: An empirical study of Taiwan and Korea. Expert Systems with Applications, 36, 6945-6955.

Currie, G., Wallis, I. (2008) Effective ways to grow urban bus markets - a synthesis of evidence. Journal of Transport Geography, 16, 419-429.

Daellenbach, H.G. and McNickle, D.C. (2005) Management science: Decision making through systems thinking, Palgrave Macmillan, China.

Danaher, A., Ryus, P., Ellis, E., Walker, M.C. and Hunter-Zaworski, K. (2003) TCRP Report 100: Transit Capacity and Quality of Service Manual, Transit Cooperative Research Program, Transportation Research Board, Washington, DC.

De Jonge, B., and Teunter, R. H. (2013).Optimizing itineraries in public transportation with walks between rides. Transportation Research Part B: Methodological, 55, 212-226.

De Oña, J., de Oña, R., Eboli, L., Forciniti, C., \&Mazzulla, G. (2016). Transit passengers' behavioural intentions: the influence of service quality and customer satisfaction. Transportmetrica A: Transport Science, 12(5), 385-412.

De Ona J., De Ona R., Eboli L., Mazzulla G., (2015) Heterogeneity in perceptions of service quality among groups of railway passengers. International Journal of Sustainable Transportation, 9 (8), 612-626.

De Ona, Rocio, Laura Eboli, and Gabriella Mazzulla. (2014) Key factors affecting rail service quality in the Northern Italy: a decision tree approach, Transport 29(1) 75-83.

Debrezion, G., Pels, E., Rietveld, P. (2006) TI 2006-031/3: The Impact of Rail Transport on Real Estate Prices: An Empirical Analysis of the Dutch Housing Markets, Tinbergen Institute Discussion Paper, VrijeUniversiteit Amsterdam and Tinbergen Institute, Amsterdam.

Debrezion, G., Pels, E., Rietveld, P. (2009)Modelling the joint access mode and railway station choice. Transportation Research Part E, 45, 270-283.

Del Castillo, J. M., \& Benitez, F. G. (2013).Determining a public transport satisfaction index from user surveys.Transportmetrica A: Transport Science, 9(8), 713-741.

Derrible S., Kennedy C. (2010) Characterizing metro networks: state, form, and structure, Transportation, 37, 275-297.

Eden C, Ackermann F. (1998) Making strategy: the journey of strategic management. London: Sage.

Geiger D., Paz A. and Pearl J. (1990) Learning causal trees from dependence information.In Proceedings of the AAAI National Conference, 770-776.

Givoni, M., \&Rietveld, P. (2007). The access journey to the railway station and its role in passengers' satisfaction with rail travel.Transport Policy, 14(5), 357-365.

Group for Urban Interchanges Development and Evaluation (GUIDE)

(1999).European Commission, the Fourth Framework Research and Technological Development Programme. Available at: <www.cordis.lu/transport/src/guide.htm $>$.

Guo, Z., Wilson, N.H.M (2011) Assessing the cost of transfer inconvenience in public transport systems: A case study of the London Underground. Transportation Research Part A, $45,91-104$.

Heckerman, D. (1997) Bayesian networks for data mining. Data Mining And Knowledge Discovery, 1, 79-119.

Hess, S., Bierlaire, M., Polak, J.W. (2005) Estimation of value of travel-time savings using mixed logit models. Transportation Research Part A, 39, 221-236. 
Janssens, D., Wets, G., Brijs, T., Vanhoof, K., Arentze, T., Timmermans, H. (2006) Integrating Bayesian networks and decision trees in a sequential rule-based transportation model. European Journal of Operational Research, 175, 16-34.

Jensen F.V. (2001) Bayesian networks and decision graphs.Springer, New York.

Kim S.H., Chung J.h., Park S., Choi K. (2017) Analysis of User Satisfaction to Promote Public Transportation: A Pattern-Recognition Approach Focusing on Out-of-Vehicle Time, International Journal of Sustainable Transportation (in press).

Kocabas, V., and Dragicevic, S. (2007).Enhancing a GIS cellular automata model of land use change: Bayesian networks, influence diagrams and causality. Transactions in GIS, 11(5), 681-702.

Lai, W. T., and Chen, C. F. (2011). Behavioral intentions of public transit passengersThe roles of service quality, perceived value, satisfaction and involvement. Transport Policy, 18(2), 318-325.

Lam T.C. and Small K.A. (2001) The value of time and reliability: measurement from a value pricing experiment. Transport Research Part E, 37, 231-251.

Lam W. and J. Morrall (1982) Bus Passenger Walking Distances and Waiting Times: A Summer-winter comparison. Transportation Quarterly, 36, 3.

Lindsey, M., Schofer, J.L., Durango-Cohen, P., Gray, K.A. (2010) Relationship between proximity to transit and ridership for journey-to-work trips in Chicago.Transportation Research Part A, 44, 697-709.

Lyons, G. andUrry, J. (2005) Travel time use in the information age. Transportation Research Part A, 39, 2-3, 257-276.

Morgan, K. (2005). Development of a preliminary framework for informing the risk analysis and risk management of nanoparticles. Risk Analysis, 25(6), 1621-1635.

Murray, A. (2001) Strategic analysis of public transport coverage.Socio-Economic Planning Sciences, 35, 3, 175-188.

Nadkarni S, Shenoy P. (2001) A Bayesian network approach to making inferences in causal maps. European Journal of Operational Research, 128,479-98.

Nadkarni S, Shenoy P. (2004) A causal mapping approach to constructing Bayesian networks. Decision Support Systems, 38, 259-81.

New York Metropolitan Transportation Council (NYMTC) (1998) The 1997/1998 Regional Travel - Household Interview Survey.

Noland R.B. and Small, K.A. (1995) Travel Time uncertainty, departure time choice and the cost of the morning commute, Annual Meeting of the Transportation Research Board, Washington, DC.

O'Sullivan, S. and Morall, J. (1996) Walking Distances to and from Light-Rail Transit stations. In Transportation Research Record 1538, TRB, National Research Council, Washington DC.

Olivková, I. (2015). Model for measuring passenger satisfaction and assessing mass transit quality.Journal of Public Transportation, 18(3), 4.

Ozer, D., Kocaman, S. (2007).The urban transportation of Istanbul: current situation, problems and recommendations. Available at $<$ http://www.thefreelibrary.com/The+urban+transportation + of + Istanbul\%3A+current + situation, + problems + and...-a021952014>

Oztaysi, B., Kaya, T., \&Kahraman, C. (2011). Performance comparison based on customer relationship management using analytic network process. Expert Systems with Applications, 38(8), 9788-9798.

Parasuraman A., Zeithaml V.A. and Berry L.L. (1985) Conceptual Model of Service Quality and its Implications for Future Research.Journal of Marketing, 49, 4, 41-50. 
Poveda-Bautista, R., Baptista, D. C., \&García-Melon, M. (2012).Setting competitiveness indicators using BSC and ANP.International Journal of Production Research, 50(17), 4738-4752.

Pradhan, M., Henrion, M., Provan, G., Favero, B.D. and Huang, K. (1996) The sensitivity of belief networks to imprecise probabilities: An experimental investigation. Artificial Intelligence, 85, 363-397.

Pratt, R.H. (2000) TCRP Web Document 12: Traveler Response to Transportation System Changes, Transit Cooperative Research Program, TRB, National Research Council, Washington, DC.

Rietveld, P. (2000). The accessibility of railway stations: the role of the bicycle in The Netherlands. Transportation Research Part D: Transport and Environment, 5(1), 71-75.

Román, C., Martín, J.C. and Espino, R., (2014). Using stated preferences to analyze the service quality of public transport. International Journal of Sustainable Transportation, $8(1)$, pp.28-46.

Roorda, M.J. and Ruiz, T. (2008) Long- and short-term dynamics in activity scheduling: A structural equations approach. Transportation Research Part A, 42, 545-562.

Sebastiani, P., \&Perls, T. T. (2008).Complex genetic models. In Bayesian Networks: A Practical Guide to Applications Edited by O. Pourret, P. Naim, B. Marcot, 53-72, John Wiley \& Sons.

Shen, W., Xiao, W., \& Wang, X. (2016). Passenger satisfaction evaluation model for Urban rail transit: A structural equation modeling based on partial least squares. Transport Policy, 46, 20-31.

Shiftan, Y., Outwater, M.L., Zhou, Y. (2008) Transit market research using structural equation modeling and attitudinal market segmentation, Transport Policy, 15, 186- 195.

Small, K.A, Winston, C., Yan, J. (2005) Uncovering the distribution of motorists' preferences for travel time and reliability.Econometrica, 73, 4, 1367-1382.

Stathopoulos, A., \&Marcucci, E. (2014). De gustibusdisputandumest: Non-linearity in public transportation service quality evaluation. International Journal of Sustainable Transportation, 8(1), 47-68.

TCRP Report 47 (1999) A Handbook for Measuring Customer Satisfaction and Service Quality, Transit Cooperative Research Program, Transportation Research Board, Washington, DC.

Transport for London (2001). London Area Travel Survey (LATS), London, UK.

Tyrinopoulos, Y., Antoniou, C. (2008) Public transit user satisfaction: Variability and policy implications. Transport Policy, 15, 260-272.

Ugurlu, Seda (2011) YolculukSüresiYeterlilikİndeksiileTürler-

ArasiUlaşimdaErişimModellemesi, PhD Thesis, Istanbul TeknikUniversitesi, Turkey.

United Nations Centre for Human Settlements (1993) Provision of travel way space for urban public transport in developing countries. Nairobi, United Nations Centre for Human Settlements (Habitat).

vanLierop, D., \& El-Geneidy, A. (2016). Enjoying loyalty: The relationship between service quality, customer satisfaction, and behavioral intentions in public transit.Research in Transportation Economics, 59, 50-59.

Vassallo J.M., Ciommo F.D., Garcia, A. (2012) Intermodal exchange stations in the city of Madrid, Transportation, 39, 975-995.

Vega, A.andFeighan-Reynolds, A. (2009) A methodological framework for the study of residential location and travel-to-work mode choice under central and suburban employment destination patterns. Transportation Research Part A, 43, 401-419.

Yilmaz, V., \& Ari, E. (2017). The effects of service quality, image, and customer satisfaction on customer complaints and loyalty in high-speed rail service in Turkey: a 
proposal of the structural equation model. Transportmetrica A: Transport Science, 13(1), 6790.

Williams, B.J., \& Cole, B. (2013). Mining monitored data for decision-making with a Bayesian network model. Ecological modelling, 249, 26-36.

Xie, F., and Levinson, D. (2007).Measuring the structure of road networks.Geographical Analysis, 39(3), 336-356.

Zheng, N., Geroliminis N. (2013) On the distribution of urban road space for multimodal congested networks, Transp. Res. Part B, 57, 326-341. 